\title{
Produtividade e vigor do maracujazeiro-amarelo plantado em covas e plantio direto sob manejo orgânico
}

\author{
Yield and vigor of the yellow passion fruit tree planted in holes and in no-tillage \\ under organic cultivation

\begin{abstract}
Sebastião Elviro de Araújo Neto ${ }^{{ }^{*}}$ Suzana Rodrigues de Souza ${ }^{\text {II }}$ Cristina Szilagyi Saldanha ${ }^{I I}$ Yrle da Rocha Fontinele ${ }^{\mathrm{II}}$ Jacson Rondinelli da Silva Negreiros ${ }^{\mathrm{III}}$ Roberval Mendes $^{\mathrm{IV}}$ José Marlo Araújo de Azevedo ${ }^{\mathrm{IV}}$ Elizangela Barboza de Lima Oliveira ${ }^{\mathrm{IV}}$
\end{abstract}

\section{RESUMO}

O objetivo deste trabalho foi avaliar o vigor e a produtividade do maracujazeiro-amarelo plantado em diferentes tamanhos de cova e plantio direto sob manejo orgânico. O experimento foi conduzido de 2005 a 2007, no Setor de Agricultura Ecológica da Universidade Federal do Acre, em delineamento de blocos casualizados, constituídos de cinco tratamentos, quatro repetições e quatro plantas por parcela. Foram avaliados cinco tipos de preparo do solo: $T_{1}$ cova do tamanho do torrão $(0,19 \times 0,063 m)$ com adubação em cobertura; $T_{2}$ cova de 0,30 × 0,30 × 0,30m com adubação de plantio na cova; $T_{3}$ cova de $0,30 \times 0,30 \times 0,30 \mathrm{~m}$ com adubação de plantio em cobertura; $T_{4}$ cova de $0,50 \times 0,50 \times$ $0,50 \mathrm{~m}$ com adubação de plantio na cova; e $T_{5}$ cova de $0,50 \times$ $0,50 \times 0,50 m$ com adubação de plantio em cobertura. $O$ tamanho da cova e o plantio direto não influenciaram o vigor da planta e a biomassa de raízes. O número de frutos por planta e a produtividade, na segunda e na somatória das duas safras, foram maiores com plantio direto e com covas cúbicas de 0,30m. Após dois anos de cultivo, a densidade do solo foi maior na camada de $0-5 \mathrm{~cm}$ de profundidade num raio de $20 \mathrm{~cm}$ da planta para o plantio em covas de $0,50 \mathrm{~m}$ com adubação na cova e menor para o plantio direto, não havendo diferença entre os demais tratamentos. O plantio direto ou o plantio em covas pequenas com dimensões de $0,30 \times 0,30 \times$ 0,30m proporcionou maior produtividade de maracujá que o plantio em covas maiores, mesmo não influenciando o vigor das plantas e a massa seca de raízes.

Palavras-chave: Passiflora edulis $f$. flavicarpa, agroecologia, sistema de plantio.

\begin{abstract}
The objective of this research was to evaluate the yield and vigor of the yellow passion fruit tree planted in hole and no-tillage under organic system. The experiment was carried under experimental design in randomized blocks with five treatments and four replicates with four plants per plot. Five types of soil tillage: $T_{1}$ - hole of the size of the clod $(0.19 \mathrm{x}$ $0.063 \mathrm{~m}$ ) with manuring in covering; $T_{2}$ - hole of $0.30 \times 0.30 \times$ $0.30 \mathrm{~m}$ with manuring addition in the hole; $T_{3}$ - similar the $T_{2}$, with manuring in covering; $T_{4}$ - hole of $0.50 \times 0.50 \times 0.50 \mathrm{~m}$ with manuring addition in the hole; and $T_{5}$ - similar the $T_{4}$, with manuring in covering were evaluated. The hole size and the no-tillage did not influence the vigor of the plant and root biomass. The number of fruits per plant and the yield in the second crop and in the total of the two crops were larger with holes of $0.30 \mathrm{~m}$ and no-tillage. After 2 years of planting, the soil bulk density was larger in the depth of $0-5 \mathrm{~cm}$ to $20 \mathrm{~cm}$ of the plant for the planting in holes of $0.50 \mathrm{~m}$ with manuring addition and smaller for the no-tillage, there was no difference among the other treatments. The no-tillage or traditional system with holes of $0.30 \times 0.30 \times 0.30 \mathrm{~m}$, provided larger passion fruit yield than the traditional systems with holes of $0.50 \times 0.50 \times$ $0.50 \mathrm{~m}$, not having an influence in the vigor of the plant and the dry mass of roots.
\end{abstract}

Key words: Passiflora edulis f. flavicarpa, agroecology, planting system.

\section{INTRODUÇÃO}

A produção de maracujá no Brasil passa por forte retração. Essa retração é causada pela

IDepartamento de Ciências Agrárias, Universidade Federal do Acre (UFAC), BR 364, km 04, Distrito Industrial, 69915-900, Rio Branco, AC, Brasil. E-mail:selviro2000@yahoo.com.br.*Autor para correspondência.

${ }^{\mathrm{II}}$ Curso de Agronomia, UFAC, Rio Branco, AC, Brasil.

IIICentro de Pesquisa Agroflorestal do Acre, Embrapa, Rio Branco, AC, Brasil.

${ }^{\text {IV C}}$ Curso de Mestrado em Produção Vegetal (UFAC), Rio Branco, AC, Brasil. 
concorrência do suco produzido no Equador (principal concorrente brasileiro), baixando o preço do suco internacional e, conseqüentemente, os preços pagos aos agricultores. Esses agricultores, por sua vez passam a investir cada vez menos nos pomares, levando ao abandono da atividade e ocasionando forte queda da oferta de maracujá para indústria (MEIRELLES, 2006).

O preparo do solo com covas grandes para o plantio do maracujazeiro-amarelo é um dos fatores que onera o custo de implantação, exige mão-de-obra (FERREIRA \& ARAÚJO NETO, 2007) e pode desestruturar o solo (SIRI-PRIETO et al., 2007). Mesmo assim, a literatura atual recomenda covas entre $0,30 \mathrm{x}$ 0,30 x 0,30m a 0,50 x 0,50 x 0,50m, inclusive em sistema orgânico (SILVA \& OLIVEIRA, 2001; PENTEADO, 2004). SIMÃO (1971) afirma que o limite do tamanho da cova deve ser estabelecido por critérios econômicos, pois tecnicamente as melhores covas são as maiores. Porém, sabe-se que, em cultivo orgânico, o revolvimento do solo, enterrando a camada orgânica, não trás benefícios para o solo e conseqüentemente para a planta (KHATOUNIAN, 2001), pois essa matéria orgânica poderá oxidar-se e transformar-se em ácidos fúlvicos que mobilizam $\mathrm{Al}^{+3} \mathrm{e} \mathrm{Fe}^{+3}$ e imobilizam cátions essenciais. Além disso, pode ocorrer a pulverização do solo e futura compactação (PRIMAVESI, 2002).

O não-revolvimento do solo e o uso de cultivo mínimo ou plantio direto melhoram a qualidade do solo, o que aumenta o carbono orgânico e a agregação das partículas diminui a densidade e aumenta a infiltração de água (HU et al., 2007; SIRI-PRIETO et al., 2007), fundamental para uma agricultura sustentável. Portanto, esses fatores estão diretamente relacionados a boas produtividades, à sanidade e ao vigor das plantas.

Além dos aspectos diretos na conservação do solo e do ambiente, o preparo do solo constitui-se em uma das técnicas demandantes de energia (mãode-obra ou combustível) e, para uma agricultura sustentável, quanto menos energia for utilizada na produção de alimentos, maior será o balanço energético e menos resíduos serão lançados no ambiente (SOUZA \& RESENDE, 2006).

Portanto, diante do exposto, o objetivo deste trabalho foi avaliar a produtividade e o vigor do maracujazeiro-amarelo plantado em diferentes tamanhos de cova e plantio direto sob manejo orgânico.

\section{MATERIAL E MÉTODOS}

O experimento foi conduzido de 2005 a 2007, na Universidade Federal do Acre (UFAC), situada em
Rio Branco, Acre, na latitude $9^{\circ} 57^{\prime} 35^{\prime}$ ' S, longitude $67^{\circ}$ 52' 08” W e altitude de $168 \mathrm{~m}$.

O delineamento experimental foi de blocos casualizados, com cinco tratamentos, quatro repetições e quatro plantas por parcela seqüenciais na mesma linha de plantio. Os tratamentos corresponderam a diferentes preparos do solo: $\mathrm{T}_{1}$ Plantio direto (cova do tamanho do torrão, medindo $0,19 \mathrm{~m} \times 0,063 \mathrm{~m}$ e com adubação em cobertura); $T_{2}$ cova de 0,30 x 0,30 x 0,30m com adubação na cova; $\mathrm{T}_{3}$ cova de 0,30 x 0,30 x 0,30m com adubação em cobertura; $\mathrm{T}_{4}$ cova de 0,50 x 0,50 x 0,50m com adubação na cova; e $\mathrm{T}_{5}$ cova de 0,50 x 0,50 x 0,50m com adubação em cobertura.

O plantio foi realizado no dia 23/11/2005, no espaçamento de 3,0 x 3,0m, em espaldeira vertical com um fio de arame a uma altura de $2 \mathrm{~m}$ do solo. A polinização das flores ocorreu de forma natural, sem interferência humana.

A adubação básica de plantio foi feita de acordo com a análise do solo: $\mathrm{pH}$ - 4,5; $\mathrm{P}$ - 6,0mg dm $\mathrm{dm}^{-3}$; $\mathrm{K}-0,31 \mathrm{cmol} \mathrm{dm}^{-3} ; \mathrm{Ca}-1,5 \mathrm{cmol} \mathrm{dm}^{-3} ; \mathrm{Mg}-1,10 \mathrm{cmol}_{\mathrm{c}}$ $\mathrm{dm}^{-3} ; \mathrm{Al}-0,50 \mathrm{cmol} \mathrm{dm}^{-3} ; \mathrm{H}+\mathrm{Al}-2,09 \mathrm{cmol} \mathrm{dm}^{-3} ; \mathrm{SB}{ }^{\mathrm{c}}$ 2,99 $\mathrm{cmol} \mathrm{dm}^{-3}$; T 5,08 $\mathrm{cmol} \mathrm{dm}^{-3}$; V 59\%; e Matéria Orgânica (M.O.) 12,1 $\mathrm{g} \mathrm{kg}^{-1}$.

A calagem não foi realizada por ser um experimento em agricultura orgânica, com baixo uso de insumos externos. Além disso, o calcário $\left(\mathrm{R} \$ 500,00 \mathrm{t}^{-1}\right)$ e os fertilizantes têm preços elevados na região. As covas foram adubadas com 10L de composto orgânico, 6L de cama-de-aviário e 200g de termofosfato (Yoorin Master $^{\circledR}$ ). As covas foram abertas nas dimensões determinadas, e o adubo foi misturado com o próprio solo e retornado à cova. Nas covas com adubação em cobertura após a abertura destas e o plantio, o adubo foi distribuído próximo à muda. Três meses após o plantio, foram aplicados 20L de cama de aviário por planta, em cobertura para todos os tratamentos.

O preparo do solo constou apenas de roçagem, abertura de covas e cobertura viva com amendoim-forrageiro (Arachis pintoi) e feijão-guandu (Cajanus cajan). No primeiro ano, foi feita uma roçagem da braquiária (Brachiaria decumbens) para implantar o maracujazeiro e mais quatro capinas para implantar e estabelecer o amendoim-forrageiro e o feijão-guandu nas entrelinhas de plantio. $\mathrm{O}$ amendoimforrageiro foi roçado mais três vezes no segundo ano, e o feijão-guandu foi podado duas vezes.

O experimento foi avaliado durante a vida útil das plantas, medindo o comprimento do ramo principal, do diâmetro do caule, da produtividade e do número de frutos por planta. Após a fase produtiva das plantas, foram avaliadas a massa seca de raiz e a densidade do solo próximo ao colo da planta. 
Para a determinação do comprimento do ramo principal, foi utilizada uma fita métrica graduada em centímetros, tomando como referência a distância do colo ao ápice do ramo de maior tamanho. Essa medição foi realizada aos 60 dias após o plantio. O diâmetro do caule foi analisado aos dois meses após o plantio (D1), aos seis meses (D2) e aos 31 meses (D3), medido a $20 \mathrm{~cm}$ do colo da planta, com auxílio de um paquímetro graduado em milímetros. A massa seca das raízes foi medida após a lavagem de amostra de solo medindo 25 × 25 x $15 \mathrm{~cm}\left(9,375 \mathrm{~cm}^{3}\right)$, coletada a $0-25 \mathrm{~cm}$ e $25-50 \mathrm{~cm}$ de distância do caule da planta na profundidade de $15 \mathrm{~cm}$, expressa em $\mathrm{kg} \mathrm{m}^{-3}$ de solo. Para estimar a produtividade, os frutos de cada parcela foram contados duas vezes por semana, e parte desses frutos foi pesada para obter o peso médio, que foi de $120 \mathrm{~g}$. Assim, a estimativa da produtividade $\left(\mathrm{t} \mathrm{ha}^{-1}\right)$ foi calculada multiplicando o número de frutos pelo peso médio. A densidade do solo a 10 e $20 \mathrm{~cm}$ do caule da planta foi analisada nas profundidades em centímetro de $0-5,10-15,20-25,30-35$. O solo foi coletado em anel volumétrico acoplado em extrator de amostras nãodeformadas. O solo foi colocado em sacos de papel, exposto em fluxo de ar aquecido em estufa a $70^{\circ} \mathrm{C}$ e pesado até peso constante. Os resultados foram expressos em $\left(\mathrm{g} \mathrm{cm}^{-3}\right)$.

A colheita da primeira safra teve início em maio de 2006, estendendo-se até agosto do mesmo ano e da segunda safra de outubro de 2006 a junho de 2007. A coleta e contagem dos frutos foram realizadas semanalmente.

Os dados foram testados em análise de variância por meio do teste $F$, e as médias foram comparadas pelo teste de Tukey (ambos a 5\% de probabilidade de erro). Foi utilizado o programa SISVAR para a análise estatística (FERREIRA, 2000).

\section{RESULTADOS E DISCUSSÃO}

Verificou-se que o tamanho da cova não afetou o comprimento dos ramos, o diâmetro do caule, a massa seca de raízes (Tabela 1 ), o número de fruto e a produtividade na $1^{\underline{a}}$ safra (Tabela 2 ), mas influenciou o número de frutos por planta e a produtividade na $2^{\text {a }}$ safra e na somatória das duas safras (Tabela 2) e a densidade do solo na profundidade de $0-5 \mathrm{~cm}$, no raio de $20 \mathrm{~cm}$ distante do colo da planta (Tabela 3).

A produtividade de maracujá no Brasil é de 13,4t ha-1 e no Acre é de 8,4t ha-1 (AGRIANUAL, 2007). Esse valor é superior ao encontrado neste trabalho (5t $\mathrm{ha}^{-1}$ ) e ambos os valores estão longe de atingir o potencial produtivo do maracujazeiro $\left(65 \mathrm{t} \mathrm{ha}^{-1}\right)$ do híbrido IAC-3 (MELETTI et al., 2000). Desse modo, uma produtividade baixa exige menos dos efeitos que podem ter os tratamentos aplicados no experimento, pois, apesar de se observar efeito do preparo do solo na produtividade, não se observou efeito no vigor da planta, medido por meio do comprimento do ramo principal, do diâmetro do caule e da massa de raiz.

Alguns estudos com plantio direto orgânico evidenciam o bom desempenho agronômico, como em alface e beringela, que revelaram não haver efeito do plantio direto e do sistema convencional de preparo de solo na produtividade das culturas (CASTRO et al., 2005; OLIVEIRA et al., 2006). Em cultivo convencional de laranjeira Frank no Rio Grande do Sul, DORNELLES (1975) verificou mesmo crescimento entre plantas sobre plantio direto e sobre covas cúbicas de $0,30 \mathrm{~m}$ e de $0,60 \mathrm{~m}$.

Tabela 1 - Comprimento do ramo, diâmetro do caule e massa seca de raízes de maracujazeiro-amarelo plantado em diferentes tamanhos de cova e plantio direto sob manejo orgânico. Universidade Federal do Acre, Rio Branco, Acre, 2007*.

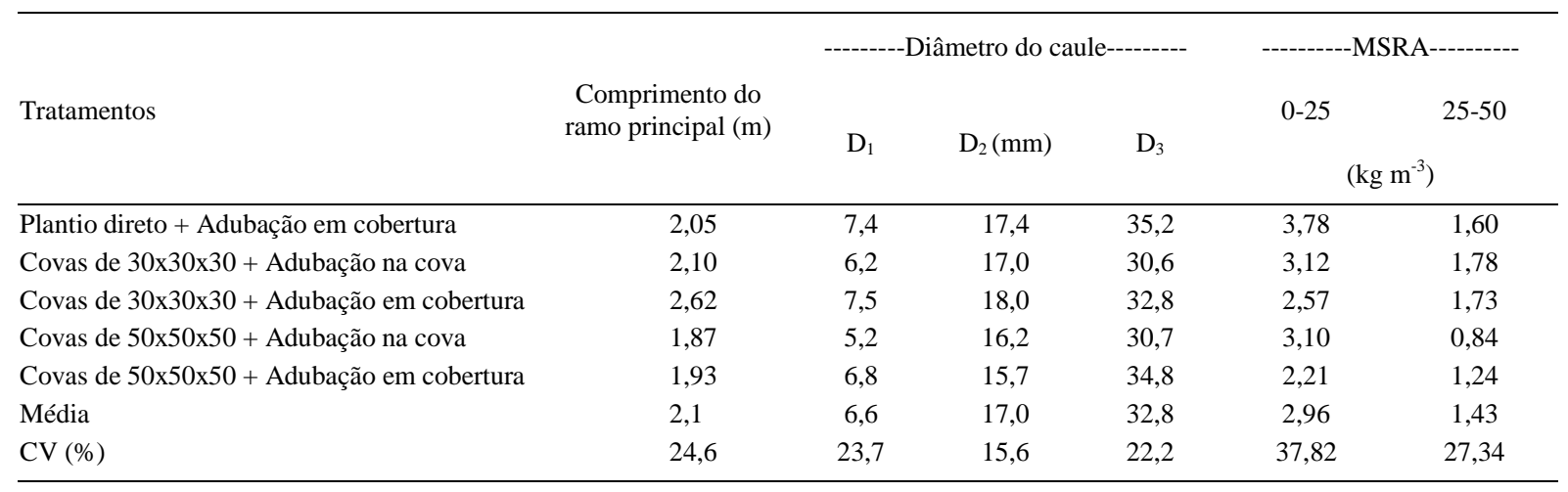

* Não houve diferença estatística para todas as características avaliadas.

$\mathrm{D}_{1}$ - (Diâmetro do caule 2 meses após o plantio - MAP); $\mathrm{D}_{2}$ - (6 MAP); $\mathrm{D}_{3}$ - (31 MAP).

MSRA - Massa seca de raízes distanciada de 0 a $25 \mathrm{~cm}$ e de 25 a $50 \mathrm{~cm}$ do caule e profundidade de $15 \mathrm{~cm}$.

Ciência Rural, v.39, n.3, mai-jun, 2009. 
Produtividade e vigor do maracujazeiro-amarelo plantado em covas e plantio direto sob manejo orgânico.

Tabela 2 - Número de frutos por planta e produtividade de maracujazeiro-amarelo plantado em diferentes tamanhos de cova e plantio direto sob cultivo orgânico. Universidade Federal do Acre, Rio Branco, Acre, 2007*.

\begin{tabular}{|c|c|c|c|c|c|c|}
\hline \multirow{2}{*}{ Tratamentos } & \multicolumn{3}{|c|}{----------Nº de frutos por planta---------- } & \multicolumn{3}{|c|}{---------Produtividade $\left(\mathrm{kg} \mathrm{ha}^{-1}\right.$ )--------- } \\
\hline & $1^{\mathrm{a} S a f r a}$ & $2^{\mathrm{a}}$ Safra & Total & $1^{\text {a }}$ Safra & $2^{\mathrm{a}}$ Safra & Total \\
\hline Plantio direto + Adub./cobertura & $21,8 \mathrm{a}$ & $61,2 \mathrm{ab}$ & $83,0 \mathrm{ab}$ & $3.829,3 a$ & $7.444,6 a b$ & $11.273,9 \mathrm{ab}$ \\
\hline Covas de 30x30x30 + Adub./cova & 15,5 a & 79.3 a & 94,8 a & $2.736,8 \mathrm{a}$ & $9.664,8$ a & $12.401,5 \mathrm{a}$ \\
\hline Covas de 30x30x30 + Adub./cobert. & 25,3 a & 73,3 a & 98,6 а & $4.177,5 a$ & $8.951,9$ a & $13.129,2$ a \\
\hline Covas de 50x50x50 +Adub./cova & $10,0 \mathrm{a}$ & 36,8 c & 46,8 c & $1.795,3 \mathrm{a}$ & $4.491,2$ c & $6.286,6$ с \\
\hline Covas de 50x50x50+Adub./cobert. & $10,8 \mathrm{a}$ & $43,8 b c$ & $54,6 \mathrm{bc}$ & $1.911,0 \mathrm{a}$ & $5.331,4 \mathrm{bc}$ & $7.242,3 \mathrm{bc}$ \\
\hline Média & 16,7 & 58,9 & 75,6 & $2.890,0$ & $7.176,8$ & $10.066,7$ \\
\hline CV (\%) & 26,49 & 10,49 & 17,93 & 28,1 & 10,42 & 10,56 \\
\hline
\end{tabular}

* Médias seguidas de letras distintas na coluna diferem entre si pelo teste de Tukey a 5\% de probabilidade de erro.

Em pesquisas com maracujazeiro-amarelo (QUEIRÓS, 1997), avaliando diferentes tamanhos e formas de covas $\left(0,125 \mathrm{~m}^{3}\right),\left(0,205 \mathrm{~m}^{3}\right)$ e $\left(0,285 \mathrm{~m}^{3}\right)$, não foi verificado efeito na produtividade e qualidade dos frutos de maracujazeiro-amarelo na Paraíba, embora o menor volume de solo revolvido nesse caso $\left(0,125 \mathrm{~m}^{3}\right)$ corresponda a uma movimentação de solo próxima ao limite superior recomendado para essa cultura (SIMÃO, 1971; SILVA\& OLIVEIRA, 2001; PENTEADO, 2004).

A produtividade das duas safras deste experimento foi de $10,2 \mathrm{t} \mathrm{ha}^{-1}$, abaixo da produtividade da região para duas safras $\left(16,8 \mathrm{t} \mathrm{ha}^{-1}\right)$. Essa baixa produtividade nos dois casos é causada em grande parte pela deficiência de polinização, um dos principais problemas do maracujá na região, decorrente da baixa população de abelhas polinizadoras (mamangavas) e do efeito negativo dos fatores abióticos (estiagem prolongada, precipitação pluviométrica excessiva na floração, solos com baixa fertilidade natural) e fatores bióticos (presença de abelhas silvestres e exóticas). Para aumentar a produtividade do maracujá orgânico na região, pode-se utilizar polinização artificial (CAMILLO, 2003), maior quantidade de adubo orgânico, aplicação de calda sulfocálcica e biofertilizantes (PENTEADO, 2004), variedades melhoradas para as condições locais (OLIVEIRA \& RUGGIERO, 1998), dentre outras alternativas tecnológicas.

A produtividade no plantio direto não diferiu do plantio em covas de $0,30 \mathrm{~m}$ e de $0,50 \mathrm{~m}$ com adubação em cobertura. Porém, no plantio direto ou na abertura de covas pequenas, como de $0,30 \mathrm{~m}$, os gastos são menores com mão-de-obra, sendo assim mais rentável (FERREIRA \& ARAÚJO NETO, 2007). Além disso, há a vantagem de proporcionar maior equilíbrio do solo, pois, segundo PRIMAVESI (2002), o revolvimento do solo, enterrando a camada orgânica natural e aquela aplicada com a adubação orgânica, pode causar acúmulo de ácidos fúlvicos pela oxidação da matéria orgânica (M.O.) enterrada. Esses ácidos mobilizam $\mathrm{Al}^{+3} \mathrm{e} \mathrm{Fe}^{+3} \mathrm{e}$ imobilizam cátions essenciais. Além disso, pode ocorrer a pulverização do solo (desestruturação natural) e a futura compactação, dificultando o crescimento radicular e o desenvolvimento da planta, o que, provavelmente, aconteceu nas covas de $0,50 \mathrm{~m}$ com adubação na cova (Tabela 3).

Um dos problemas da desestruturação do solo com sistema de coveamento, principalmente com aterro da M.O., é a compactação. No presente estudo, verificou-se que a desestruturação do solo na confecção das covas não manteve essa densidade, pois, após dois anos de cultivo, a densidade do solo no local das covas era a mesma que o plantio direto, exceto quando foram feitas covas de $0,50 \mathrm{~m}$ e adubação na cova, apresentando solo mais denso que o plantio direto na camada de $0-5 \mathrm{~cm}$ a $20 \mathrm{~cm}$ do colo (Tabela 3 ). Nos demais sistemas de plantio, a densidade praticamente não foi alterada em comparação ao plantio direto.

Na camada de $0-5 \mathrm{~cm}$ de profundidade, há grande interferência biológica do solo promovida pela adubação em cobertura. SIRI-PRIETO et al. (2007) relatam que a não-inversão das camadas de solo durante seu preparo melhora a qualidade deste, aumentando o carbono orgânico, diminuindo a densidade e aumentando a infiltração de água. HU et al. (2007) afirmam que a longo prazo o plantio direto aumenta a agregação e a estabilidade dos agregados do solo.

\section{CONCLUSÃO}

O plantio direto ou em covas pequenas com dimensões de $0,30 \times 0,30 \times 0,30 \mathrm{~m}$ proporciona maior

Ciência Rural, v.39, n.3, mai-jun, 2009. 
Tabela 3 - Densidade aparente do solo a 10 e 20cm do caule de plantas de maracujazeiro-amarelo plantads em diferentes tamanhos de cova e plantio direto sob cultivo orgânico. Universidade Federal do Acre, Rio Branco, Acre, 2007*.

\begin{tabular}{|c|c|c|c|c|c|c|c|c|}
\hline \multirow{3}{*}{ Tratamentos } & \multicolumn{8}{|c|}{------------------------------Densidade aparente do solo $\left(\mathrm{g} \mathrm{cm}^{-3}\right.$ )----------------------------- } \\
\hline & \multicolumn{4}{|c|}{--------------à 10cm do caule------------- } & \multicolumn{4}{|c|}{-------------à 20cm do caule-------------- } \\
\hline & $0-5^{*}$ & $10-15$ & $20-25$ & $30-35$ & $0-5$ & $10-15$ & $20-25$ & 30-35 \\
\hline Plantio direto + Adub./cobertura & $1,30 \mathrm{a}$ & $1,38 \mathrm{a}$ & $1,45 \mathrm{a}$ & $1,46 \mathrm{a}$ & $1,25 \mathrm{~b}$ & $1,45 a$ & $1,48 a$ & $1,48 \mathrm{a}$ \\
\hline Covas de 30x30x30 + Adub./cova & $1,27 \mathrm{a}$ & $1,35 \mathrm{a}$ & $1,38 \mathrm{a}$ & $1,47 \mathrm{a}$ & 1,34ab & $1,42 \mathrm{a}$ & $1,45 \mathrm{a}$ & $1,54 \mathrm{a}$ \\
\hline Covas de 30x30x30 + Adub./cobert. & $1,30 \mathrm{a}$ & $1,32 \mathrm{a}$ & 1,43a & $1,41 \mathrm{a}$ & 1,33ab & $1,57 \mathrm{a}$ & $1,40 \mathrm{a}$ & $1,58 \mathrm{a}$ \\
\hline Covas de 50x50x50 + Adub./cova & $1,35 \mathrm{a}$ & $1,38 \mathrm{a}$ & $1,28 \mathrm{a}$ & $1,31 \mathrm{a}$ & 1,37 a & $1,46 a$ & 1,43a & $1,47 a$ \\
\hline Covas de 50x50x50+Adub./cobert. & $1,36 a$ & $1,10 \mathrm{a}$ & 1,43a & $1,49 \mathrm{a}$ & 1,32ab & $1,45 a$ & $1,50 \mathrm{a}$ & $1,47 \mathrm{a}$ \\
\hline Média & 1,32 & 1,31 & 1,40 & 1,43 & 1,32 & 1,47 & 1,45 & 1,51 \\
\hline CV (\%) & 5,22 & 25,53 & 6,05 & 6,21 & 3,18 & 5,53 & 5,47 & 4,90 \\
\hline
\end{tabular}

* Médias seguidas de letras distintas na coluna diferem entre si pelo teste de Tukey a 5\% de probabilidade de erro.

produtividade de maracujá que o plantio em covas maiores, mesmo não influenciando o vigor das plantas e a massa seca de raízes próxima à planta.

\section{REFERÊNCIAS}

AGRIANUAL 2007. Maracujá. In: Anuário da agricultura brasileira. São Paulo: FNP Consultoria, 2007. p.387-395.

CAMILlo, E. Polinização do maracujá. Ribeirão Preto: Holo, 2003. 44p.

CASTRO, C.M. de et al. Plantio direto, adubação verde e suplementação com esterco de aves na produção orgânica de berinjela. Pesquisa Agropecuária Brasileira, Brasília, v.40, n.5, p.495-502, 2005. Disponível em: http://www.scielo.br/ scielo.php ? s cript = sci_art text \& pi d = S $0100-$ 204X2005000500011\&lng=en\&nrm=iso\&tlng=pt. Doi: 10.1590/ S0100-204X2005000500011.

DORNELLES, C.M.M. Experimento comparativo de tamanho de covas e método de aplicação de adubação em plantio de laranjeira (Citrus sinensis Osbeck). In: CONGRESSO BRASILEIRO DE FRUTICULTURA, 3., 1975, Rio de Janeiro. Anais... Rio de Janeiro: Sociedade Brasileira de Fruticultura, 1975. p.359-363.

FERREIRA, D.F. Análises estatísticas por meio do Sisvar para Windows versão 4.0. In: REUNIÃO ANUAL DA REGIÃO BRASILEIRA DA SOCIEDADE INTERNACIONAL DE BIOMETRIA. 45., 2000, São Carlos, SP. Anais... São Carlos: UFSCar, 2000. p.255-258.

FERREIRA, R.L.F.; ARAÚJO NETO, S.E. de. Rentabilidade econômica do maracujazeiro-amarelo plantado em plantio direto sob manejo orgânico. In: CONGRESSO BRASILEIRO DE AGRoeCOLOGIA, 5., 2007, Guarapari. Revista Brasileira de Agroecologia. Rio Grande do Sul: Sociedade Brasileira de Agroecologia, 2007. V.2. p.125-128.
HU, Z. et al. Influence of Conservation Tillage on soil aggregates features in North China plain. Agricultural Sciences in China, v.6, n.9, p.1099-1106, 2007. Disponível em: http://www.sciencedirect.com/ science?_ob=ArticleURL\&_udi=B82XG-4PXFY2XB\&_user=687358\&_rdoc $=1 \& \_f m t=\& \_o r i g=$ search \&_sort $=d \& v i e w=c$ \&_acct $=$ C000037899\&_version $=1 \&$ \&_urlVersion $=0 \&$ _ userid $=687358 \&$ md5 $=27359 b 6 b 3705 e 1 c 113 f 4 c b 7716 d b e b 6 e$. Doi: 10.1016/S1671-2927(07)60152-7.

KHATOUNIAN, C.A. A reconstrução ecológica da agricultura. Botucatu: Agroecologia, 2001. 348p.

MEIRELLES, M.C. Maracujá maravilha. Frutas e derivados, São Paulo, v.1, n.4, p.31-33, 2006.

MELETTI, L.M.M. et al. Melhoramento do maracujazeiroamarelo: obtenção do cultivar 'Composto IAC-27'. Scientia Agricola, Piracicaba, v.57, n.3, p.491-498, 2000.

OLIVEIRA, J.C.; RUGGIERO, C. Aspecto sobre o melhoramento do maracujazeiro-amarelo. In: SIMPÓSIO BRASILEIRO SOBRE A CULTURA DO MARACUJAZEIRO, 5., 1998, Jaboticabal. Anais... Jaboticabal: Funep, 1998. p.291-310.

OLIVEIRA N.G. et al. Plantio direto de alface adubada com "cama” de aviário sobre coberturas vivas de grama e amendoim forrageiro. Horticultura Brasileira, Brasília, v.24, p.112117, 2006.

PENTEADO, S.R. Fruticultura orgânica: formação e condução. Viçosa: Aprenda Fácil, 2004. 308p.

PRIMAVESI, A. Manejo ecológico do solo: a agricultura em regiões tropicais. São Paulo: Nobel, 2002. 541p.

QUEIRÓS, M.S. de. Tipos de covas e cobertura morta sobre a produção e qualidade dos frutos do maracujazeiro amarelo. 1997. 67f. Dissertação (Mestrado em Manejo e Conservação de Solos) - Programa de Pós-graduação em Manejo e Conservação de Solos, Universidade Federal da Paraíba/Areia. 
SILVA, J.R. da; OLIVEIRA, H.J. de. Implantação da cultura, manejo e tratos culturais. In: BRUCKNER, C.H.; PICANÇO, M.C. Maracujá: tecnologia de produção, pós-colheita, agroindústria, mercado. Porto Alegre: Cinco continentes, 2001. p.139-162.

SIMÃO, S. Manual de fruticultura. São Paulo: Agronômica Ceres, 1971. 530p.

SIRI-PRIETO, G. et al. Tillage systems for a cotton-peanut rotation with winter-annual grazing: Impacts on soil carbon, nitrogen and physical properties. Soil \& Tillage
Research, Amsterdam, v. 96, p. 260-268, 2007. Disponível em: http://www.sciencedirect.com/ science?_ob=ArticleURL\&_udi=B6TC6-4PB15Y 5$18 \_u s e r=687358 \& \_r d o c=18 \_f m t=\& \_o r i g=s e a r c h \& \_s o r t=d \& v i e w=c \&$ _acct $=$ C000037899\&_version $=1 \&$ _urlVersion $=0 \&$ \&us erid $=687358 \&$ md5 $=8818$ d8286c0f5ea57dbe6d15d9959b4e. Doi: $10.1016 /$ j.still.2007.06.010.

SOUZA, J.L de; RESENDE, P. Manual de horticultura orgânica. 2.ed. Viçosa: Aprenda Fácil, 2006. 843p. 